\title{
MACAM-MACAM TIPE DATA
}

\author{
AGUS NUGROHO \\ 185110007 \\ Fakultas Komputer \\ Agusnugroho.student@umitra.ac.id
}

\begin{abstract}
Bahasa $\mathrm{C}$ adalah sebuah bahasa pemrograman yang dipakai untuk membuat suatu program komputer. Bahasa C dirancang oleh DENNIS M. RITCHIE Bahasa C adalah sebuah bahasa pemrograman yang dipakai untuk membuat suatu program komputer. Di dalam $\mathrm{C}$ terdapat dua tipe data dasar, tipe data dasar standar dan tipe data user defined. tipe data dasar standar digolongkan menjadi beberapa bagian didalam beberapa macam tipe data. Setiap tipe data mempunyai ukuran dan range (jangkauan). Ketika pemrograman, kita menyimpan variabel di memori komputer kita, tapi komputer harus mengetahui jenis data yang ingin kita simpan di dalamnya, karena tidak akan menduduki jumlah yang sama memori untuk menyimpan sejumlah sederhana daripada untuk menyimpan sebuah huruf tunggal atau sejumlah besar, dan mereka tidak akan ditafsirkan dengan cara yang sama. Memori di komputer kita adalah terorganisir dalam byte. Byte adalah jumlah minimum memori yang kita dapat mengatur di $\mathrm{C}++$. Sebuah byte dapat menyimpan jumlah yang relatif kecil data: satu karaekter tunggal atau integer kecil (biasanya sebuah integer antara 0 dan 255).
\end{abstract}

Kata Kunci :Macam-Macam Tipe Data 


\section{A. PENDAhuluan}

Bahasa $\mathrm{C}$ adalah sebuah bahasa pemrograman yang dipakai untuk membuat suatu program komputer. Bahasa $\mathrm{C}$ dirancang oleh DENNIS M. RITCHIE Bahasa $\mathrm{C}$ adalah sebuah bahasa pemrograman yang dipakai untuk membuat suatu program komputer. Di dalam $\mathrm{C}$ terdapat dua tipe data dasar, tipe data dasar standar dan tipe data user defined. tipe data dasar standar digolongkan menjadi beberapa bagian didalam beberapa macam tipe data.Memori di komputer kita adalah terorganisir dalam byte. Byte adalah jumlah minimum memori yang kita dapat mengatur di $\mathrm{C}++$. Sebuah byte dapat menyimpan jumlah yang relatif kecil data: satu karaekter tunggal atau integer kecil (biasanya sebuah integer antara 0 dan 255). Selain itu, komputer dapat memanipulasi lebih kompleks jenis data yang berasal dari pengelompokan beberapa byte, seperti nomor panjang atau non-integer angka. Selanjutnya Anda memiliki ringkasan dari tipe data dasar fundamental dalam $\mathrm{C}++$, serta berbagai nilai-nilai yang dapat direpresentasikan dengan masing-masing:Untuk menyimpan suatu variabel diperlukan tempat $10-37$ to 1038 . Besar dan tipe dari Variabel-variabel di dalam standar program $\mathrm{C}++$ dispesifikasikan 


\section{B. PEMBAHASAN / STUDI KASUS}

\section{Tipe Data Dasar Standar}

Ketika pemrograman, kita menyimpan variabel di memori komputer kita, tapi komputer harus mengetahui jenis data yang ingin kita simpan di dalamnya, karena tidak akan menduduki jumlah yang sama memori untuk menyimpan sejumlah sederhana daripada untuk menyimpan sebuah huruf tunggal atau sejumlah besar, dan mereka tidak akan ditafsirkan dengan cara yang sama. Memori di komputer kita adalah terorganisir dalam byte. Byte adalah jumlah minimum memori yang kita dapat mengatur di $\mathrm{C}++$. Sebuah byte dapat menyimpan jumlah yang relatif kecil data: satu karaekter tunggal atau integer kecil (biasanya sebuah integer antara 0 dan 255). Selain itu, komputer dapat memanipulasi lebih kompleks jenis data yang berasal dari pengelompokan beberapa byte, seperti nomor panjang atau non-integer angka. Selanjutnya Anda memiliki ringkasan dari tipe data dasar fundamental dalam $\mathrm{C}++$, serta berbagai nilai-nilai yang dapat direpresentasikan dengan masing-masing:Untuk menyimpan suatu variabel diperlukan tempat 10-37 to 1038

Besar dan tipe dari Variabel-variabel di dalam standar program $\mathrm{C}++$ dispesifikasikan sebagai berikut.

\begin{tabular}{|c|c|c|c|}
\hline char & $\begin{array}{l}\text { Abjad/karakte } \\
\mathrm{r} \text { atau untuk } \\
\text { bilangan bulat } \\
\text { kecil }\end{array}$ & 1 byte & $\begin{array}{l}\text { signed: }-128 \text { to } \\
\text { 127unsigned: } 0 \\
\text { to } 255\end{array}$ \\
\hline $\begin{array}{l}\text { short } \\
\text { int } \\
\text { (short) }\end{array}$ & $\begin{array}{l}\text { Bilangan } \\
\text { bulat dengan } \\
\text { jangkauan } \\
\text { pendek }\end{array}$ & 2 byte & $\begin{array}{l}\text { signed: }-32768 \\
\text { to } \\
32767 \text { unsigned: } \\
0 \text { to } 65535\end{array}$ \\
\hline int & $\begin{array}{l}\text { Bilangan } \\
\text { bulat }\end{array}$ & 4 byte & $\begin{array}{l}\text { signed: - } \\
\text { 2147483648 to } \\
\text { 2147483647unsi } \\
\text { gned: } 0 \text { to } \\
\text { 4294967295 }\end{array}$ \\
\hline $\begin{array}{l}\text { long } \\
\text { int } \\
\text { (long) }\end{array}$ & $\begin{array}{l}\text { Integer } \\
\text { dengan } \\
\text { jangkauan } \\
\text { panjang }\end{array}$ & 4 byte & $\begin{array}{l}\text { signed: - } \\
\text { 2147483648 to } \\
2147483647 \text { unsi } \\
\text { gned: } 0 \text { to } \\
4294967295\end{array}$ \\
\hline bool & $\begin{array}{l}\text { Boolean, } \\
\text { dapat bernilai } \\
\text { benar atau } \\
\text { salah }\end{array}$ & 1 byte & $\begin{array}{l}\text { (true or false) } \mathrm{i} \\
\text { byte true or } \\
\text { false }\end{array}$ \\
\hline float & $\begin{array}{l}\text { Angka } \\
\text { dengan titik } \\
\text { mengambang } \\
\text { (bilangan } \\
\text { cacah) }\end{array}$ & 4 byte & $10-37$ to 1038 \\
\hline double & $\begin{array}{l}\text { Bilangan } \\
\text { cacah dengan } \\
\text { ketelitian } \\
\text { ganda }\end{array}$ & 8 byte & $10-307$ to 10308 \\
\hline $\begin{array}{l}\text { long } \\
\text { double }\end{array}$ & $\begin{array}{l}\text { Bilangan } \\
\text { cacah dengan } \\
\text { ketelitian } \\
\text { ganda } \\
\text { panjang }\end{array}$ & 8 byte & 8 byte \\
\hline $\begin{array}{l}\text { wchar } \\
\text {-t }\end{array}$ & $\begin{array}{l}\text { Karakter } \\
\text { lebar, biasa } \\
\text { dipakai untuk } \\
\text { Unicode } \\
\text { karakter }\end{array}$ & 2 byte & 1 karakter lebar \\
\hline
\end{tabular}

\begin{tabular}{|l|l|l|l|}
\hline Nama & Keterangan & Ukuran & Jangkauan \\
\hline
\end{tabular}


* Nilai kolom Ukuran dan Rentang tergantung pada sistem program untuk dikompilasi. Nilai-nilai yang ditunjukkan di atas adalah yang ditemukan pada kebanyakan sistem 32-bit. arti dari unsingned yaitu tipe data nya tidak bertanda (+/-), semuanya bernilai mutlak. signed berarti tipe datanya bertanda (+/-).

Ada 2 kategori dari tipe data standar yaitu:

\section{TIPE DASAR}

\section{a. Bilangan bulat (integer)}

- Bilangan atau angka yang tidak memiliki titik desimal atau pecahan, seperti $10,+225,-10,+25$.

- Tipe dituliskan sebagai integer atau int

- Jangkauan nilai bergantung pada implementasi perangkat keras komputer, misalnya dari $-11 \mathrm{~s} / \mathrm{d}+12$; untuk algoritma tidak kita batasi.

- Operasi aritmetik: tamabah+, kurang-, kali*, bagi/, sisa hasil bagi\%

- Operasi pembanding:lebih kecil=, sama $=$, tidak sama $><$.

\section{b. Bilangan biasa (real)}

- Bilangan atau angka yang bisa memiliki titik desimal atau pecahan, dan ditulis sebagai : $235.45,+13.99$, 87.76 atau dalam notasi ilmiah seperti : 1.245E+03, 7.45E-02, dsb.

- Tipe dituliskan sebagai : real
- Jangkauan nilai : bergantung pada implementasi perangkat keras komputer, misalnya dari $-2.9 \mathrm{E}-39 \mathrm{~s} / \mathrm{d}$ $+1.7 \mathrm{E}+38$, untuk algoritma tidak dibatasi.

- Operasi aritmatik dan pembandingan juga berlaku bagi bilangan biasa.

\section{c. Bilangan tetap (const)}

- Bilangan tetap ( const ) adalah tipe bilangan, tidak bernilai bulat maupun tidak, yang nilainya tidak berubah selama algoritma dilaksanakana.

- Tipe dituliskan sebagai const .

- Jangkauan nilai meliputi semua bilangan yang mungkin.

\section{d. Karakter (character)}

- Karakter adalah data tunggal yang mewakili semua huruf, simbol baca, dan juga simbol angka yang tidak dapat dioprasikan secara matematis, misalnya: 'A', 'B', ...., 'Z', '?', ',', dst.

- Tipe dituliskan sebagai char

- Jangkauan nilai meliputi semua karakter dalam kode ASCII, atau yang tertera pada setiap tombol keyboard.

- Operasi pembanding dapat dilakukan dan dievaluasi menurut urutan kode ASCII, sehingga huruf 'A' (Hex 41) sebenarnya lebih kecil dari huruf 'a' (Hex 61)

\section{e. Logik ( logika)}

- Tipe data logik adalah tipe data yang dipergunakan untuk memberi nilai 
pada hasil pembandingan, atau kombinasi pembandingan.

- Tipe dituliskan sebagai boolean (tipe data ini digunakan untuk pengambilan keputusan dalam operasi logika. Terdiri dari true disimbolkan ' $\mathrm{T}$ ' dan False yang disimbolkan ' $F$ '. Ketika kita ingin mendapatklan hasil yang valid/pasti, kita menggunakan tipe data boolean untuk memperoleh keputusan dalam suatu penyelesaian yang pasti)

- Jangkauan nilai ada dua : true dan false

- Biasanya digunakan pada operasi for, perulangan while, perulangan dowhile.

\begin{tabular}{|c|l|}
\hline Logika & \multicolumn{1}{|c|}{ Keterangan } \\
\hline$\& \&$ & Logika dan(AND) \\
\hline II & Logika or (ATAU) \\
\hline$!$ & Logika not(LINGKARAN) \\
\hline
\end{tabular}

\section{TIPE BENTUKAN}

\section{a. Array ( larik )}

- Array adalah tipe data bentukan, yang merupakan wadah untuk menampung beberapa nilai data yang sejenis. Kumpulan bilangan bulat adalah array integer, kumpulan bilangan tidak bulat adalah array real.

- Cara menefinisikan ada 2 macam, yaitu:

* Nilai_ujian : array [ 1..10] of integer, atau

* Int nilai-_ujian[10];
- Kedua definisi diatas menunjukkan bahwa nilai_ujian adalah kumpulan dari 10 nilai bertipe bilangan bulat.

\section{b. String}

- String adalah tipe data bentukan yang merupakan deretan karakter yang membentuk satu kata atau satu kalimat, yang biasanya diapit oleh dua tanda kutip.

- Sebagai contoh: nama, alamat, dan judul adalah tipe string.

- Cara mendefinisikannya adalah:

* string nama, alamat; atau

* nama,alamat : string;

\section{c. Record ( rekaman )}

- Record adalah tipe data bentukan yang merupakan wadah untuk menampung elemen data yang tipenya tidak perlu sama dengan tujuan mewakili satu jenis objek. Datanya berupa campuran dari tipe data seperti string, numerik, char, boolean, atau tipe data lainnya. Tipe data ini merupakan struktur dasar dari suatu sistem database.

- Sebagai contoh, mahasiswa sebagai satu jenis objek memiliki beberapa elemen data seperti : nomer_stb, nama, umur, dll.

- Cara mendefinisikan record mahasiswa tersebut adalah sebagai berikut:

Type dataMhs : record

Nama_mhs : string,

Umur : integer, 


\section{d.Tipe Data Citra}

-Berisi grafik/gambar yang banyak digunakan pada aplikasi video.

-Example : Grafik perkembangan jumlah penduduk.

Tipe data yang ada di bahasa $\mathrm{C}++$ dapat di lihat di bawah ini :

\begin{tabular}{|c|c|}
\hline TIPE DATA & $\begin{array}{c}\text { Penentu Format } \\
\text { Untuk Printf() }\end{array}$ \\
\hline Integer & $\% \mathrm{~d}$ \\
\hline Floating Point & $\% \mathrm{f}$ \\
\hline $\begin{array}{l}\text { Bentuk } \\
\text { Berpangkat }\end{array}$ & $\%$ e \\
\hline $\begin{array}{l}\quad \text { Bentuk } \\
\text { Desimal dan } \\
\text { Pangkat }\end{array}$ & $\% \mathrm{~g}$ \\
\hline Double Precision & $\%$ lf \\
\hline Character & $\% \mathrm{c}$ \\
\hline String & $\% \mathrm{~s}$ \\
\hline Unsigned Integer & $\% \mathrm{u}$ \\
\hline Long Integer & $\%$ ld \\
\hline $\begin{array}{l}\text { Long Unsigned } \\
\text { Integer }\end{array}$ & $\%$ lu \\
\hline $\begin{array}{l}\text { Unsigned } \\
\text { Hexadecimal } \\
\text { Integer }\end{array}$ & $\% \mathrm{x}$ \\
\hline $\begin{array}{l}\text { Unsigned Octal } \\
\text { Integer }\end{array}$ & $\% 0$ \\
\hline
\end{tabular}

\section{Ketidakakuratan secara Numerik}

Representational error : kesalahan yang berkaitan dengan pengkodean bilangan real menggunakan jumlah digit biner yang terbatas. Untuk variabel yang mengontrol perulangan sebaiknya digunakan variabel integer, tidak variabel real.

Cancellation error : kesalahan sebagai akibat operasi aritmetika pada operan- operan dengan magnitude yang berbeda; sehingga pengaruh dari operand yang nilainya kecil hilang. Arithmetic underflow : kesalahan yang disebabkan karena hasil komputasi yang nilainya berbeda sangat tipis dengan bilangan bulat.

contoh : nilai yang dihasilkan sebuah fungsi adalah 4,9999999. Oleh program, nilai ini tidak dibulatkan secara otomatis. Namun, dalam bahasa manusia nilai $4,9999999 \approx 5$

Arithmetic overflow : kesalahan yang disebabkan karena kita berusaha menyatakan hasil komputasi yang terlalu besar.

contoh : nilai yang dihasilkan sebuah fungsi, pembilang dan penyebut dimana nilai penyebutnya 0 , maka hasilnya adalah nilai tak hingga $(\infty)$, disebut stack value.

\section{B. Tipe Data User Defined}

\section{Tipe Enumerasi}

Tipe enumerasi adalah tipe data yang nilai-nilainya ditentukan oleh programer pada saat deklarasi tipe. Merupakan tipe data yang memiliki elemen-elemen tertentu yang disebut satu/satu dari bernilai konstanta integer sesuai dengan urutannya. Pada tipe data ini elemen masukan diwakili oleh suatu nama variable yang ditlis di dalam kurung.

Example :

Indeks_Hari $=($ Nol, Minggu, Senin, Selasa, Rabu, Kamis, Jumat, Sabtu)

Konstanta enumerasi :

- suatu identifier yang merupakan salah satu nilai dalam tipe enumerasi 
- Harus berupa identifier

- Tidak boleh numerik, karakter atau string

- Secara default, nilainya diawali dengan integer 0 .

- Suatu identifier tidak boleh muncul lebih dari sekali dalam definisi tipe enumerasi.

Contoh : nilai $\pi=3,14$

\section{IMPLEMENTASI}

\section{FUNGSI DALAM OPERASI STRING}

\section{Untuk Meng-Copy String}

strcpy (katal, kata2); meng-copy isi dari kata1 ke kata2

\section{Untuk Mengetahui Panjang String}

strlen ()

strlen (string); mereturn bilangan bulat yang menyatakan panjang string

//misalkan terdapat 2 buah string untuk percobaan

char katal[10] = "Latihan";

char kata2[20] = "Coba”;

\section{Untuk Menggabungkan String}

strcat(kata1, kata2); //menggabungkan string menjadi "Latihan Coba"

\section{Untuk Mengkoversikan Ke} Huruf Kapital strupr(katal);//merubah kata1 menjadi "LATIHAN"

\section{Untuk Mengkoversikan Ke Huruf} Kecil

strlwr(kata2);//merubah kata2 menjadi "coba"

\section{Untuk Mencari Substring}

strstr(katal, kata2);//kata1 bukan substring kata2, karana string "Latihan" tidak ada dalam string "Coba"

\section{Untuk Mengembalikan String}

strrev(kata2); //merubah string "Coba" menjadi "aboC"

\section{OPERASI LOGIKA}

//Salah satu penggunaan operasi logika \#include <string.h>

\#include <iostream.h>

\#include <conio.h>

$\operatorname{main}()$

\{

int $x$; //deklarasi variabel

clrscr () ; // clear screen

cout $<<$ "Masukkan Nilai $x=$ "; cin $>>$; 
if $(x>20 \& \& x<30)$ //operator logika AND

cout $<<$ "Nilai $x$ masuk dalam range I";

else if $(x>=10 \quad \| x<20)$ //operator logika OR

\{

if $(!(x<10))$ //operator NOT

cout $<<$ Nilai $x$ masuk dalam range II";

else

cout $<<$ "Nilai $x$ tidak masuk dalam range";

\}

getche ();

\}

\section{OPERASI ARRAY}

Beberapa contoh penggunaan array:

\section{Inisialisasi Array Berdimensi Dua}

contoh : int data $[2][5]=\{\{2,3,4,5$, 2\},

$\{4,2,6,2,7\}$,

\};

/* Inisialisasi Array Dimensi 2 */

\#include <conio.h> \#include <stdio.h>

\#include<iostream.h>

void main()

\{

int $i, j$;

int data[2][5] $=\{\{2,3,4,5,2\}$,

$\{4,2,6,2,7\}\}$

$\operatorname{clrscr}()$;

for $(i=0 ; i<2 ; i++)$

\{

$\operatorname{for}(j=0 ; j<5 ; j++)$

\{

cout $<<$ data $[i][j]$;

cout $<<$ " ";

\}

cout $<<e n d l$;

\}

$\operatorname{getch}()$;

\} 


\section{Inisialisasi Array Berdimensi Satu}

contoh : float nilai[5] $=\{56.5,66.7$, 87.45, 98,5, 78.9 \};

/* Inisialisasi Array Dimensi 1 */

\#include $<$ conio.h $>$

\#include<iostream.h>

\#include<iomanip.h>

void main()

\{

int nilai $[5]=\{56,67,57,76,72\}$;

int $i$;

$\operatorname{clrscr}()$;

for $(i=0 ; i<5 ; i++)$

\{

cout $<<$ "Nilai Array Index ke " $<<i<<"="$;

cout $<<<a<<e n d l$;

\}

$\operatorname{getch}()$;

\}

\section{Menentukan Bilangan Genap}

\#include "stdafx.h"

\#include<iostream.h>

\#include $\langle$ conio.h $>$ int A[10];

void main()

\{

cout $<<$ "Program Array Tugas Pendahuluan Modul 4" <<endl;

cout $<<"==============$ $================"<$ $<$ endl;

cout $<<e n d l$;

int $i=0$;

while $(i<10)$

\{

cout $<<$ "nilai larikA ke " $<<i<<$ "=";

$\operatorname{cin}>>A[i]$

$i=i+1$;

\}

cout $<<e n d l$;

cout $<<$ "bilangan genap yang ada dalam larikA : ";

for $(i=0 ; i<10 ; i++)$

\{

if $(A[i] \% 2==0)$

\{

cout $<<A[i]<<$ ” ";

\} 
else

continue;

\}

cout $<<e n d l$;

$\operatorname{getch}()$;

\section{ID SECURITY}

QWTD4452377-ASP-5244107

\section{KESIMPULAN}

Tipe data dalam pemrograman $\mathrm{C}++$ membunyai beberapa macam variabel. Setiap variabel mempunyai fungsi dan jangkauan yang berbeda-beda. Tipe data dibagi menjadi dua, tipe data standar dan tipe data user defined Ada 2 kategori dari tipe data standar yaitu tipe dasar dan tipe bentukan. Tipe bentukan adalah kumpulan dari beberapa tipe data dasar. Di dalam penggunaan tipe data standar, ada beberapa kestidakakuratan yang mungkin terjadi. Diantaranya ada 4 macam ketidakakuratan. Sedangkan di tipe data user defined, berbeda dengan tipe data standar. Bedanya, jika tipe data standar adalah nilai dan variabelnya sudah tersedia di memori sedangkan tipe data user defined adalah tipe data yang nilai-nilainya ditentukan oleh progammer/pengguna. Di tipe data user defined, ada beberapa bersyaratan saat akan membuat konstanta tipe enumerasi.

\section{E. DISKUSI}

Saya : Apakah artikel ini membantu anda?

RIO : Sangat membantu sekali karena saya ingin belajar tentang struktur data ,dan artikel ini mudah di pahami karena menggunakan bahasa yang mudah untuk di mengerti bagi kalangan mahasiswa seperti saya.

Saya : Apa kekurangan artikel ini?

ROBI :Mungkin tambahkan lagi sedikit tentang penjelasan macammacam tipe data dengan ditambahkan foto saat membuat program aplikasi.

Saya : Apa kelebihan artikel ini?

VERY :Kelebihan artikel ini adalah penjelasnya sangat sigkat padat dan jelas.

Saya : Apakah artikel ini layak di publikasi?

DION : menurut saya artikel ini layak jika di publiksaikan, karena membantu mahasiswa untuk mencari informasi tentang macam-macam tipe data dengan mudah. 


\section{F. REFERENCE}

[1] O. M. Febriani and A. S. Putra, "Sistem Informasi Monitoring Inventori Barang Pada Balai Riset Standardisasi Industri Bandar Lampung," J. Inform., vol. 13, no. 1, pp. 90-98, 2014.

[2] A. S. Putra, "Paperplain: Execution Fundamental Create Application With Borland Delphi 7.0 University Of Mitra Indonesia," 2018.

[3] A. S. Putra, "2018 Artikel Struktur Data, Audit Dan Jaringan Komputer," 2018.

[4] A. S. Putra, "ALIAS MANAGER USED IN DATABASE DESKTOP STUDI CASE DB DEMOS."

[5] A. S. Putra, "COMPREHENSIVE SET OF PROFESSIONAL FOR DISTRIBUTE COMPUTING."

[6] A. S. Putra, "DATA ORIENTED RECOGNITION IN BORLAND DELPHI 7.0."

[7] A. S. Putra, "EMBARCADERO DELPHI XE 2 IN GPUPOWERED FIREMONKEY APPLICATION."

[8] A. S. Putra, "HAK ATAS KEKAYAAN INTELEKTUAL DALAM DUNIA TEKNOLOGY BERBASIS REVOLUSI INDUSTRI 4.0."

[9] A. S. Putra, "IMPLEMENTASI PERATURAN PERUNDANGAN UU. NO 31 TAHUN 2000 TENTANG DESAIN INDUSTRI BERBASIS INFORMATION TECHNOLOGY."

[10] A. S. Putra,
"IMPLEMENTATION OF PARADOX DBASE."

A. S. Putra, "IMPLEMENTATION OF TRADE SECRET CASE STUDY SAMSUNG MOBILE PHONE."

[12] A. S. Putra, "IMPLEMENTATION

PATENT FOR APPLICATION WEB BASED CASE STUDI WWW. PUBLIKLAMPUNG. COM."

[13] A S. Putra "IMPLEMENTATION SYSTEM FIRST TO INVENT IN DIGITALLY INDUSTRY."

[14] A. S. Putra, "MANUAL REPORT \& INTEGRATED DEVELOPMENT

ENVIRONMENT BORLAND DELPHI 7.0."

[15] A. S. Putra, "PATENT AS RELEVAN SUPPORT RESEARCH."

[16] A. S. Putra, "PATENT FOR RESEARCH STUDY CASE OF APPLE. Inc."

[17] A. S. Putra, "PATENT PROTECTION FOR APPLICATION INVENT."

[18] A. S. Putra, "QUICK REPORT IN PROPERTY PROGRAMMING."

[19] A. S. Putra, "REVIEW CIRCUIT LAYOUT COMPONENT

REQUIREMENT ON ASUS NOTEBOOK."

[20] A. S. Putra, "REVIEW TRADEMARK PATENT FOR INDUSTRIAL TECHNOLOGY BASED 4.0."

[21] A. S. Putra, "TOOLBAR COMPONENT PALLETTE IN 
OBJECT

ORIENTED

PROGRAMMING."

[22] A. S. Putra, "WORKING DIRECTORY SET FOR PARADOX 7."

[23] A. S. Putra, "ZQUERY CONNECTION IMPLEMENTED

PROGRAMMING STUDI CASE PT. BANK BCA Tbk."

[24] A. S. Putra, D. R. Aryanti, and I. Hartati, "Metode SAW (Simple Additive Weighting) sebagai Sistem Pendukung Keputusan Guru Berprestasi (Studi Kasus: SMK Global Surya)," in Prosiding Seminar Nasional Darmajaya, 2018, vol. 1, no. 1, pp. 85-97.

[25] A. S. Putra and O. M. Febriani, "Knowledge Management Online Application in PDAM Lampung Province," in Prosiding International conference on Information Technology and Business (ICITB), 2018, pp. 181-187.

[26] A. S. Putra, O. M. Febriani, and B. Bachry, "Implementasi Genetic Fuzzy System Untuk Mengidentifikasi Hasil Curian Kendaraan Bermotor Di Polda Lampung," SIMADA (Jurnal Sist. Inf. dan Manaj. Basis Data), vol. 1, no. 1, pp. 21-30, 2018.

[27] A. S. Putra, H. Sukri, and K. Zuhri, "Sistem Monitoring Realtime Jaringan Irigasi Desa (JIDES) Dengan Konsep Jaringan Sensor Nirkabel," IJEIS (Indonesian J. Electron. Instrum. Syst., vol. 8, no. 2, pp. 221-232.

[28] D. P. Sari, O. M. Febriani, and
A. S. Putra, "Perancangan Sistem Informasi SDM Berprestasi pada SD Global Surya," in Prosiding Seminar Nasional Darmajaya, 2018, vol. 1, no. 1, pp. 289-294. 